DOI: $10.5455 / 2320-1770.1 j \operatorname{cog} 20141247$

Case Report

\title{
Quandary of migrated IUCD
}

\section{Divya Pandey*, Sudha Salhan}

Department of Obstetrics \& Gynaecology, North Delhi Municipal Corporation Medical College and Hindu Rao Hospital, Delhi-7, India

Received: 21 August 2014

Accepted: 19 September 2014

\author{
*Correspondence: \\ Dr. Divya Pandey, \\ E-mail: dr_devya1@yahoo.co.in
}

Copyright: ( ) the author(s), publisher and licensee Medip Academy. This is an open-access article distributed under the terms of the Creative Commons Attribution Non-Commercial License, which permits unrestricted non-commercial use, distribution, and reproduction in any medium, provided the original work is properly cited.

\begin{abstract}
Intra Uterine Contraception Device (IUCD) is the most widely used method of reversible contraception. However complications are known to occur with IUCD. Although uterine perforation is not very rare, but asymptomatic migration into urinary bladder and mesoappendix, is a very rare occurrence. We hereby report two such cases. Two cases of migrated IUCD into urinary bladder and mesoappendix is described here. Both case remained asymptomatic over years and diagnosed incidentally. But IUCD was retrieved in both by surgical means. Owing to possibility of potential complications and medico-legal concerns due to migrated IUCD, it needs to be removed even in asymptomatic cases.
\end{abstract}

Keywords: Misplaced intra uterine contraceptive device, Copper-T, Intra-vesical migration, Mesoappendix

\section{INTRODUCTION}

An Intra-Uterine Contraceptive Device (IUCD) is a safe and cost-effective means of contraception. ${ }^{1}$ Currently it is the most widely used method of reversible contraception. $^{2}$ Although uterine perforation by IUCD is not uncommon, but intra-vesical migration is a rare complication and so is the migration to mesoappendix. ${ }^{3}$ The reported incidence of perforation by IUCD is 0.87 per 1000 insertions. ${ }^{4}$ Due to mostly asymptomatic nature of perforation the true incidence of the uterus perforation is most likely under-reported. ${ }^{5}$

This series describe two cases of intravesical and mesoappendiceal IUCD penetration which were completely asymptomatic and discovered incidentally.

\section{CASE REPORT}

\section{Case 1}

Mrs X, 28 years old P1L1A1 female, was referred to our institution with an ultrasound (USG) report showing possibility of IUCD perforating anterior myometrium and encroaching urinary bladder. She had one normal vaginal delivery followed by a missed abortion at 10 weeks for which suction and evacuation with IUCD ( $\mathrm{Cu}$ T-380A) insertion was done 4 years back. This USG was done when patient went to a Health Centre for IUCD removal and the Obstetrician couldn't localise the thread. On presentation she was absolutely asymptomatic with normal vitals, clinical history and physical findings. Thus, a CT scan was advised for exact localisation of IUCD which confirmed anterior myometrium perforation with invasion of bladder wall (Figure 1). Cystoscopy showed, horizontal limb of IUCD perforating through bladder dome wall. Laparoscopy was done which was proceeded to laparotomy in view of dense bowel adhesions obscuring the uterus and bladder. Meticulous dissection with adhesiolysis was done to expose the uterus and bladder which were densely adherent to each other. IUCD was embedded partly (vertical limb) in uterus and partly (horizontal limb) in bladder dome wall (Figure 2). Cystotomy of about $0.5 \mathrm{~cm}$ was done at bladder dome to retrieve horizontal limb while vertical limb was retrieved from myometrium. Bladder and uterus 
were repaired. Urinary catheter was kept for 7 days. Postoperative period was uneventful. Patient was discharged with advice to practice contraception atleast over next 2 years, early antenatal booking and elective Caesarean Section at term in next pregnancy.

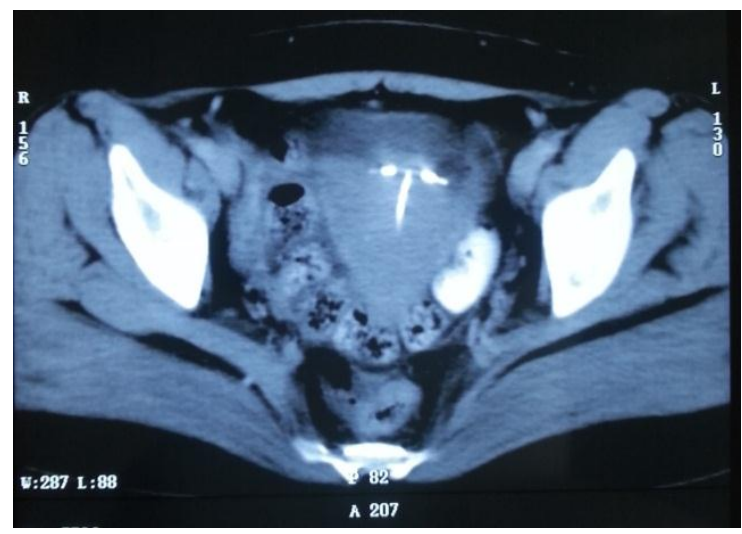

Figure 1: CT scan showing the IUCD perforating anterior myometrium and encroaching bladder wall in case 1.

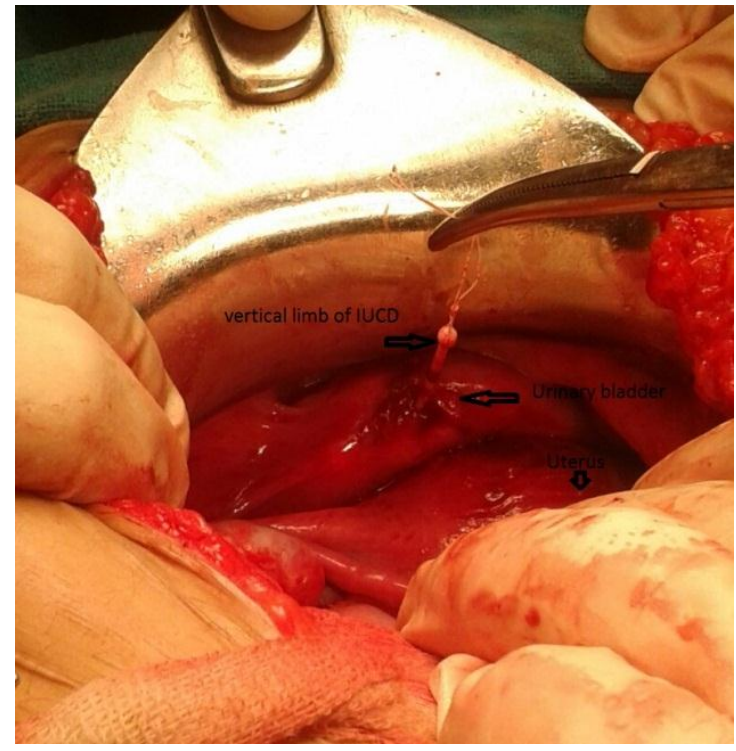

Figure 2: Intraoperative photograph showing vertical limb of IUCD retrieved from uterus and horizontal limb still inside the bladder.

\section{Case 2}

A 30 years old third gravida with two living issues came to family planning OPD, with 2 months amenorrhea and history of IUCD (Copper T-380A) insertion 2 years back, for permanent family planning procedure (tubal ligation). Per speculum examination didn't show the IUCD string. Per-vaginal examination showed 10 weeks gravid uterus. USG confirmed 10 weeks pregnancy but IUCD couldn't be localized in utero. Plain X-ray (abdomen) showed IUCD in pelvis in right iliac fossa (Figure 3). Suction and evacuation followed by laparoscopic ligation was done, but since IUCD was not retrieved so laparotomy was done. IUCD was seen in mesoappendix with dense adhesions all around. IUCD removed and appendicectomy was done.

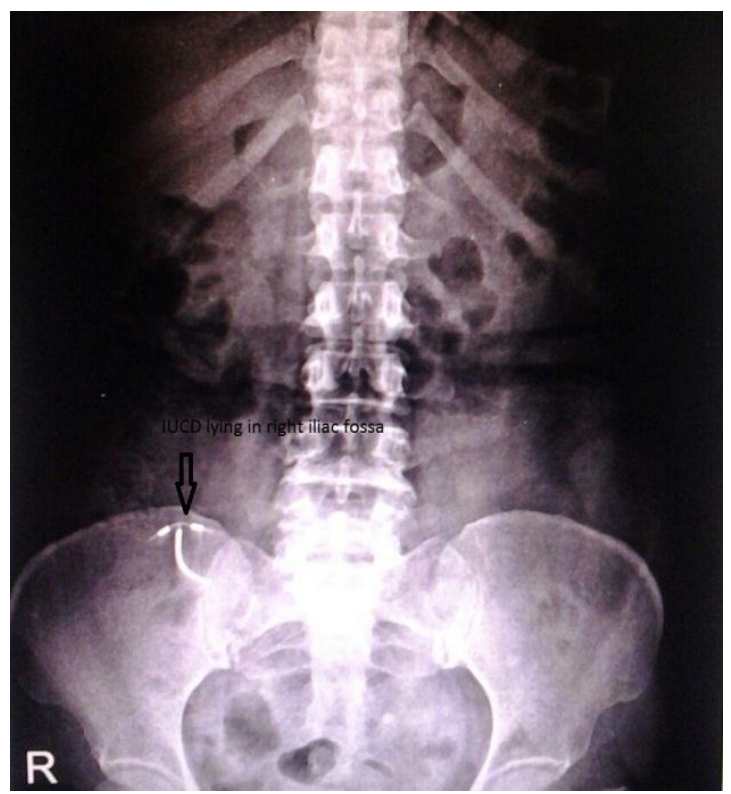

Figure 3: Plain radiograph of abdomen (A-P view) showing IUCD lying in right iliac fossa.

\section{DISCUSSION}

The most common presenting complaint in IUCD users is non-perception of IUCD string which may be due to retraction, expulsion or perforation. The uterine perforation can be partial or complete depending on involvement of all uterine layers (viz. endometrium, myometrium and serosa).

Most perforated and misplaced IUCDs are asymptomatic or may have abdominal or pelvic sign and symptoms based on the IUCD location. In both our cases, there was complete uterine perforation and both patients were asymptomatic. They were asymptomatic because of the unique location i.e. myometrium and bladder wall in case 1 and mesoappendix in case 2 where they were sealed off owing to the dense peritoneal reaction leading to dense fibrosis, giving a sealing effect. Although asymptomatic, the intravesical migration warrants its removal as left intravesical IUCD can lead to calculus formation and hence urological symptoms. ${ }^{6}$ Calculus formation may be related to the duration since penetration of IUCD into bladder and the nature of IUCD. ${ }^{7}$ For other sites removal is important to prevent complications like bladder/gut perforation and adhesion. In view of risk of adhesion formation and possibility of injury to bowel and bladder, surgical removal of intra-abdominal migrated IUCD is recommended.

Removal of misplaced asymptomatic IUCD is also important from medico-legal point of view, as this may 
lead to mal-practices claims made by the patient anxious about her perforated IUCD.

Copper IUCD are especially known for abundant inflammatory reaction and adhesions. In both our patients, copper IUCD was used leading to abundant dense adhesions which led laparoscopy to proceed to laparotomy.

An IUCD inside the peritoneal cavity can lead to gut injury, obstruction, abscess or even fistula formation. Bowel perforation may lead to peritonitis, stricture and presents with fever, pain and intermittent diarrhoea. Important factors leading to perforation and migration of IUCD are operator's experience, uterine size, position, timing of insertion, congenital uterine anomalies and scarred uterus. In both our patients, IUCD was inserted in post-partum uterus and perforation probably occurred owing to thinning and atrophy due to hypoestrogenism. Moreover during uterine involution, strong uterine contractions and soft consistency increase the risk. ${ }^{5}$

These cases demonstrate that uterine perforation and even the dislocation or intravesical migration can go unnoticed. Especially in patients with non-perception of the IUCD thread, a thorough clinico-radiological search must be made so that complication like this can be avoided. As all IUCDs are radio-opaque, plane radiograph along with USG and CT scan can be helpful in detecting missing IUCD as was done in our cases. This is done by X-ray and USG of abdomen and pelvis. Invasive methods are laparoscopy and hysteroscopy. CT scan is recommended in case bowel or bladder is suspected to be involved for exact localisation.

Laparoscopy has a better view, magnification, cosmesis advantage and short hospital stay. Laparotomy should be the last resort. Although minimal invasive technique is the preferred approach for misplaced IUCD removal, however clinical situations like extensive adhesion, bowel obstruction/perforation, bladder wall perforation or severe sepsis warrant use of trans-abdominal access by laparotomy. 8 In a review of 165 cases, omentum, rectosigmoid, peritoneum, bladder, appendix, small bowel, adnexa and iliac vein were the location of migrated IUCD. ${ }^{9}$

\section{CONCLUSION}

There should be proper patient selection by thorough history and clinical examination. Informed consent should be imparted to the client about the possible potential complications and stress should be laid upon importance of checking device thread regularly and regular follow up. Correct placement should be done only by trained personnel. In case of missing IUCD thread, thorough search should be made with high index of suspicion (whether expelled or dislocated/migrated) IUCD even in asymptomatic woman.

Funding: No funding sources

Conflict of interest: None declared

Ethical approval: Not required

\section{REFERENCES}

1. Cheng D. The intrauterine device: still misunderstood after all these years. South Med J. 2000;93:859-64.

2. Oruc S, Vatansever HS, Karaer O, Cskicioglu F, Narlikuyu B. Changes in distribution patterns of integrins in endometrium in Copper $\mathrm{T} 380$ intrauterine device uses. Acta Histochem. 2005;107:95-103.

3. Demirci D, Ekmekcioglu O, Demirtas A, Gulmez I. Big bladder stones around an intravesical migrated IUD. Int Urol Nephrol. 2003;35:495-6.

4. Markovitch O, Klein Z, Gidoni Y, Holzinger M, Beyht Y. Extrauterine mislocated IUD. Is surgical removal mandatory? Contraception. 2002;66:105-8.

5. Tosun M, Celik H, Yavuz E, Cetinkaya MB. Intravesical migration of an intrauterine device detected in a pregnant woman. Can Urol Assoc J. 2010;4:E141-3.

6. Sagnak L, Ersoy H, Aksun F, Ozok U, Karakoyunlu $\mathrm{N}$, Topaloglu H. Migration of a forgotten intrauterine device into the urinary bladder. Gulhane Med J. 2013 Sep;55:220-3.

7. Dede SF, Dilbaz B, Sahin D, Dilbaz S. Vesical calculus formation around a migrated CuT 380A. Eur J Contracept Reprod Health Care. 2006;11:50-2.

8. Sinha M, Gupta R, Tiwari A. Minimally invasive surgical approach to retrieve migrated intrauterine contraceptive device. Int J Reprod Contracept Obstet Gynaecol. 2013 Jun;2(2):147-51.

9. Kassab B, Audra P. The migrating intrauterine device: a case report and review of the literature. Contracept Fertil Sexual (French). 1999;27:696-700.

DOI: $10.5455 / 2320-1770$. ijrcog20141247

Cite this article as: Pandey D, Salhan S. Quandary of migrated IUCD. Int J Reprod Contracept Obstet Gynecol 2014;3:1110-2. 